\title{
Product Strategies and Survival in Schumpeterian Environments: Evidence from the US Security Software Industry
}

\author{
Marco S. Giarratana and Andrea Fosfuri
}

Marco S. Giarratana Carlos III University, Madrid, Spain

Andrea Fosfuri Carlos III University, Madrid, Spain

\begin{abstract}
This paper seeks to explore the drivers of survival in environments characterized by high rates of entry and exit, fragmented market shares, rapid pace of product innovation and proliferation of young ventures. The paper aims to underscore the role played by postentry product strategies, along with their interaction, after carefully controlling for 'at entry' factors and demographic conditions. Based on a population of 270 firms that entered the US security software industry between 1989 and 1998, we find evidence that surviving entities are those that are more aggressive in the adoption of versioning and portfolio broadening strategies. In particular, focusing on any one of these two strategies leads to a higher probability of survival as opposed to adopting a mixed strategy.
\end{abstract}

Keywords: survival, versioning, portfolio broadening, young ventures, software

It is well known that success factors in a stable, consolidated industry (e.g. cars, tyres, computers) are rather distinct from those observed in a more uncertain and dynamic environment, such as biotechnology (Ilinitch et al. 1996). While in the former, scale economies are a necessary, albeit insufficient, condition for achieving competitive advantage, in the latter, firm size is a relatively less important success factor. Indeed, it is hardly surprising given that the biotechnology industry, for example, comprised more than 600 publicly traded companies in 2003 (Ernst \& Young 2004). What are then the drivers of success in such turbulent and constantly morphing environments?

This paper addresses this research question by empirically examining the drivers of a firm's survival in a Schumpeterian environment, i.e. an environment where entry and exit barriers are small, economies of scale play a marginal role, the pace of product innovation is fast, and firms' competencies are put through a fierce selection process (Covin and Slevin 1989; Schmalensee 2000). Typically, one can observe such conditions in the early stages of the evolutionary development of an industry (Klepper 2002). For instance, the car industry in the 1920s was much more dynamic and uncertain than it is nowadays (Dobrev et al. 2002). However, Schumpeterian environments might sometimes constitute the DNA code for some specific industries. Examples include laser, software, semiconductors and biotechnology (Barnett and Freeman 2001; McKendrick et al. 2003), which have shown little sign of consolidation over time. 
Specifically, our contribution is to emphasize the impact of post-entry product strategies on a firm's survival beyond 'at entry' factors and initial conditions which have been identified as determinants of survival by the industrial organization literature (Audretsch 1991; Klepper 2002), and after controlling carefully for environmental and demographic conditions (Hannan 1997). In Schumpeterian environments, the rapid pace of product innovation together with greater dynamism and uncertainty ensure that product strategies are vital, whereas entry factors and initial conditions are less important.

In order to address our research question, we draw on a population of 270 firms that entered the US security software industry (SSI) from its inception in 1989 till 1998. The SSI is a relatively recent segment of the software industry, and constitutes a quintessential example of a Schumpeterian environment. The SSI is an interesting test-bed for several reasons:

1 It is a technology-based industry where product innovation plays a major role.

2 It displays significant activity in terms of entry and exit, with little sign of consolidation around a few large players.

3 Entry and exit barriers as well as scale economies are rather low.

4 Competition is mostly among young ventures, whereas mature de alio entrants are marginal players.

A distinguished feature of our research setting in comparison with previous industry studies, e.g. computer hardware (Sorenson 2000), cars and tyres (Carroll et al. 1996; Dobrev et al. 2002; Klepper 2002), is the peculiar nature of these products; this makes product strategies even more interesting. Software products tend to depreciate in value over time much faster than physical products. Additionally, software manufacturers have more horizontally differentiated offerings within a product category because of the low marginal cost of increasing scope (Gandal 2001).

We find evidence that surviving entities are those that are more aggressive in the adoption of versioning and portfolio broadening strategies. By versioning, we mean a strategy that implies the generation of multiple releases of a product within a given niche, whereas portfolio broadening occurs when a firm's product strategy covers several industry niches. Moreover, we show that focusing on any one of the two product strategies commands a higher survival probability than when adopting a mixed strategy which encompasses both a versioning and a portfolio broadening strategy. So, a unique strategic orientation helps firms to increase their probability of survival. We find this result consistent with the organizational learning (March 1991; Barnett and Sorenson 2002) and resource partitioning literature (Carroll 1985; Kim et al. 2003). Interestingly enough, other things being equal, pioneers do not enjoy a significantly higher likelihood of survival, whereas technological capabilities play an important role.

This paper is related to several streams of literature. In the industrial organization tradition, while several investigations have already studied industry-level determinants of survival, such as sector characteristics, IPR regimes, availability of venture capital (Gans and Stern 2003), much less is known about firm-specific 
drivers of survival. The finding on which the literature agrees is that survival is directly influenced by a firm's age and size (Audretsch 1991; Gerosky 1995). In Schumpeterian environments, on the contrary, the dominant organizational form is the new or very young venture, while larger established corporations have widely known difficulties in competing successfully (Tushman and Anderson 1986). Hence, when dealing with young firms, size and age represent a far too grainy image (Miller and Friesen 1984). Recently, some authors have highlighted the role of initial capabilities and entry timing as the two most important determinants of survival for new ventures (Klepper 2002). However, little attention has been devoted to the analysis of post-entry product strategies, which is our main concern here.

From a different tradition, population ecologists have extensively analysed the determinants of a firm's survival (Freeman and Hannan 1989; Carroll and Hannan 1989). Age and density are repeatedly reported as the two major drivers for death rates (Hannan et al. 1998a,b). On the other hand, product strategies have received attention only recently (Bayus and Agarwal 2006). Using data on the US automobile industry, Carroll et al. (1996) show that survival rates are lower in periods of product differentiation, although such a variable is not firmspecific. Sorenson (2000) analyses the effect of product culling on market exit in the workstation industry. He shows that product breadth (i.e. a larger number of products) has a negative impact on the likelihood of exit, although with a declining effect, as the number of rivals' offerings increases. Dobrev et al. (2002) argue that the degree of niche width has a positive effect on survival in turbulent and uncertain environments; however, its effect on more stable, concentrated markets is the opposite. All these papers have analysed a single product strategy dimension. Firms have either a broad product line or focus their activity on a specific product niche. We expand the product strategy space by introducing the versioning dimension. Versioning is especially important in the software industry (Shapiro and Varian 1998), and more so in those environments where the degree of product obsolescence is extremely high (Garud and Kumaraswamy 1993).

\section{Theoretical Background and Hypotheses}

Following the seminal work of Abernathy and Utterback (1978), several scholars have focused their attention on the ways industries evolve and their implications for strategy. Most industries are believed to follow an evolutionary pattern known as the 'industry life cycle'. A salient characteristic of this pattern is that, after an initial period of very intensive entry and exit, the industry is subject to a 'shake-out' phase which leads to higher concentration, fewer opportunities to improve products and the emergence of a dominant design (Klepper 2002). Organizational ecologists have also analysed the processes related to evolving markets and social structures over time (Hannan 1997). However, the consolidation level of a population has been considered as part of the broader environment because it is assumed to be relatively immutable with respect to short-term firm movements and strategic action (Dobrev et al. 2002). 
Schumpeterian environments are common in the early phases of the industry life cycle. However, time can pass without the industry going through any 'shake-out' phase (Dobrev et al. 2002: 236). In fact, some recent evidence has highlighted the fact that industry consolidation is not as ubiquitous as it had been initially suggested. The laser, semiconductor and biotechnology industries provide good examples of how entry and exit rates can remain intense during the whole industry life cycle (McKendrick et al. 2003; Barnett and Freeman 2001). In addition, in recent years, some industries have evolved from oligopolistic environments to become Schumpeterian ones due to exogenous shocks, for instance, deregulation. In other words, Schumpeterian environments are not an exclusive feature of the early phases of the industry life cycle.

While in more stable and consolidated environments, superior performances are most likely to be driven by cost advantages based on the exploitation of scale economies, in Schumpeterian environments there is 'a fundamental shift in the rules of competition and the way the game of competition is played' (Ilinitch et al. 1996). In this context, competition is a steady and self-reinforcing process that triggers internal organizational learning aimed at the exploration of new alternatives, as the Red Queen model postulates (Barnett and Sorenson 2002). Therefore, successful firms need to continually improve their competitive advantage and, given the limited investment in capital-intensive methods of production, keep small the minimum efficient scale. As a consequence, firms can try to experiment because the costs associated with entry and exit strategies are negligible (Geroski 1995).

Post-entry strategies are therefore particularly important here because firms that rest on their laurels, i.e. at entry factors and initial conditions, are condemned to a premature exit. Among all post-entry strategies, our focus is on product space for two reasons. First, product introduction represents a measurable and visible (especially for competitors) realization of a firm's strategy, and so it takes a prominent position inside the range of potential strategic moves (Siggelkow 2003). Second, product innovation is extremely important because new versions and product categories proliferate rapidly, thereby making older product generations obsolete.

Specifically, we distinguish between two product strategies: versioning and portfolio broadening. By versioning, we mean a strategy that implies the generation of multiple releases of a product within a single niche, whereas portfolio broadening occurs when the firm's product strategy covers several industry niches.

\section{Versioning}

As suggested by Barnett and Sorenson (2002) among others, rivalry is a major cause of poor firm performance, in the long term, that triggers internal organizational learning processes in the search for new alternatives. Competitive forces generate continuous turbulence and rapid product devaluation. In addition, the low entry barriers that characterize Schumpeterian environments facilitate the entry of new rivals endowed with innovative products that threaten incumbents in their core product niches. When the organizational population includes different cohorts, firms face more constraints in their various 
co-evolutionary survival struggles because learning from competitors is a more difficult process. This is likely to lower viability (Dowell and Swaminathan 2000; Barnett and Sorenson 2002). In this respect, versioning signals a firm's potential and intention to keep its core products updated continually, thereby managing to stay ahead of competitors.

A second theoretical argument comes from economies of learning-by-doing. Firms, through continuous refinements of their products, can develop versions that work better and match more closely the needs of their customers. This is especially important in Schumpeterian environments where product innovation usually has a strong customer-driven component (Schmalensee 2000). In order to create and sustain product success, firms should be highly responsive to consumer needs and feedback (Von Hippel 1986; Torrisi 1998; Gandal 2001). Versioning signals a proactive market orientation with continual and quick responses to suggestions and criticism from the customer.

H1: In Schumpeterian environments, firms that adopt an aggressive versioning strategy exhibit higher survival rates.

However, versioning has its inherent costs that are related to short product life spans and potential cannibalization among different product generations. Hence, too much versioning might impede the firm from recouping its investment in product innovation. This negative consequence is less likely to occur when versioning impinges on economies of substitution and modularity (Garud and Kumaraswamy 1993). Firms must use learning from competitors and customers to upgrade and enhance their knowledge base, and preserve it partially across product generations. This reflects not only a firm's ability to absorb new information, but also its capability to exploit synergies between new external knowledge and existing internal competencies. The development of modular extensions to existing products is, indeed, a peculiar feature of many security software firms, especially related to firewall, antivirus and Internet applications.

\section{Portfolio Broadening}

Portfolio broadening implies offering a large menu of products from different sub-segments of the product space. Firms with broad product lines can charge higher prices or garner greater market shares because they produce goods and services that fit more closely the diverse preferences of different consumer segments.

A broad product scope is particularly important when environmental uncertainly is high and bounded rational managers do not know ex-ante the distribution of consumer preferences and their rivals' product offerings. Product variety allows managers to hedge their bets (Sorenson 2000). Similarly, Dobrev et al. (2002) argue that the benefit of product portfolio broadening is greater in more unstable environments. Moreover, portfolio broadening could be used to raise entry barriers (Lancaster 1990), an important strategic move when there are no initial sunk costs. By saturating the product space, the firm makes it more difficult for de novo competitors to enter niches that have already been occupied. 
Portfolio broadening could also be the necessary pre-condition for pursuing a bundling strategy. According to Gandal et al. (2002), product bundling leads to superior performance either when consumer preferences for different products are positively correlated, or if the main customers are organizations that have average multiple agent preferences.

H2: In Schumpeterian environments, firms that adopt an aggressive portfolio broadening strategy exhibit higher survival rates.

Needless to say, the benefits of product variety must be traded off with increasing production, coordination and inventory costs. However, the empirical evidence so far has remained inconclusive about the magnitude of such costs. For instance, Kekre and Srinivasan (1990) find no evidence that broad lines increase either inventories or the direct costs of production, once firm scale effects are controlled for. In addition, population ecologists have suggested that the benefits of broad scope might sometimes be outweighed by increased competition from different niche specialists within the expanded scope (e.g. Dobrev et al. 2001). It remains, therefore, an empirical issue to test which effect ultimately prevails.

\section{Mixed Strategy}

The natural question that now arises is how the strategies of versioning and portfolio broadening interact with each other. If versioning leads to higher performance and so too does portfolio broadening, one could easily argue that pursuing both simultaneously should increase viability. However, based on organizational learning theory (Cyert and March 1963; March 1991) we maintain the opposite. The basic assumption behind our argument is that versioning and portfolio broadening are governed by different sets of codes and routines. In fact, versioning implies the continuous search for the best-of-breed products in a given category. To reduce the costs of cannibalization among product generations, firms need to develop the ability to update their products without destroying their existing knowledge base (Garud and Kumaraswamy 1993). This process is sometimes driven by local or incremental search (March 1991). By contrast, portfolio broadening requires routines that allow the firm to deal with a variety of customers, technologies, employee skills and other factors of production. Firms need to develop recombinant capabilities in order to hedge across distinct fields (Kim et al. 2003). Given the strong path dependence of organizational learning, positive feedback can further accentuate the differences in codes and routines behind the two strategies (March 1991). Hence, a firm that is pushing its core product to the limit, through versioning, enjoys smaller marginal benefits from broadening its product scope because of the significant trade-off between the two learning processes. Pushing this logic a step further one can establish a parallel with the exploitation/exploration dichotomy analysed by March (1991). Our argument would confirm that exploitation and exploration do not mix well - an established wisdom in the organizational learning literature.

The trade-off between versioning and portfolio broadening can be accommodated within the resource partitioning theory as well (Carroll 1985; Dobrev 
et al. 2001). According to this theory, when the environment shows a heterogeneous resource distribution and some organizations dominate a particular resource area, other organizations can survive only by moving away and adapting to new market areas. Hence, the only sustainable equilibrium is one in which firms adopt different strategies aimed at competing within distinct resource spaces (Kim et al. 2003: 1282). The trade-off between strategies provides the micro-dynamics that naturally lead to an evolution of a population into two (or more strategic) groups (Carroll 1985: 1272). For instance, the population of successful firms can be split into a set of generalists that offer a comprehensive product line, and a set of specialists competing to offer the best quality in each product category, while natural selection wipes out firms that do not execute a clear, focused strategy.

H3: In terms of viability, (a) the marginal benefit resulting from a versioning strategy decreases the more a firm pursues a product portfolio strategy; $(b)$ the marginal benefit resulting from a portfolio broadening strategy decreases the more a firm pursues a versioning strategy.

\section{Research Setting}

The US security software industry (SSI) provides our test-bed. The SSI is one of the newer segments of the software industry, a quintessential example of Schumpeterian environments (Giarratana 2004). The SSI has experienced an unprecedented growth in recent years. The world market for the SSI reached US\$4.4 billon in 1999; up from \$3.2 billion in 1998 and \$2.2 billion in 1997. In 1999, the US market alone accounted for about $70 \%$ of world revenues in the SSI (International Data Corporation 1999).

The technological foundation of the industry dates back to the late 1970s, when the US government made important investments in military projects linked to the security of data transmission. However, it was not until the late 1980s that commercial versions of software security products were released onto the civilian market. The inception of the industry therefore coincided with the growing market for home personal computers and the development of the Internet. This, in turn, created a growing commercial demand with different requirements that broadened the spectrum and complexity of the required products and services. Specifically, the first software security product that we are aware of was released by McAfee in 1989 (Infotrac PROMT database).

Figure 1 shows the number of firms that entered and exited the US SSI and the observed hazard rates. This graph highlights the high industry turbulence, given the steady increase in the rates of entry and exit throughout the period. In part this can be explained by the relatively small sunk costs needed to start an SSI venture: the initial amount invested to set up CheckPoint, the fourth largest SSI firm in 1998 with $\$ 142$ million sales, was only $\$ 300,000$ (Electronic Business 1999). 
Figure 1.

Entry, Exit and Hazard Function, 1989-2000

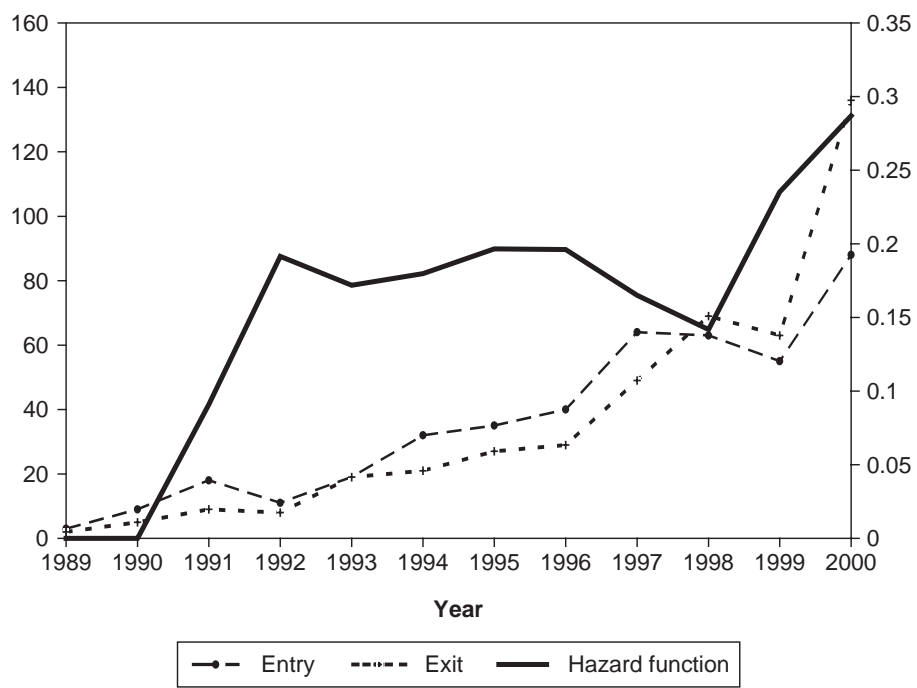

Note $: \mathrm{X}$ axis $=$ year; $\mathrm{Y}$ axis $($ left $)=$ number of firms; $\mathrm{Y}$ axis $($ right $)=$ hazard

To date, the SSI includes a wide range of products: from basic security software, such as virtual private networks, firewall and virus scanning, to advanced security services such as public key infrastructures, security certification and penetration testing. Table 2 shows the major product niches in SSI according to a six-digit SIC code classification.

The design of the security cover for an IT system is a complex undertaking. The technological core of the product is the crypto-algorithm, which specifies the mathematical transformations that are performed on the data. Speed of mathematical calculations and security level are the two main features by which SSI products are evaluated. This is because the time consumed by the encryption and decryption processes depends on the length of mathematical algorithms and the power of computing machines (Giarratana 2004). The main buyers of SSI products are large hardware and software producers, telecommunication companies, credit card administrators, banks, financial institutions and online resellers.

\section{Data and Methodology}

\section{Population Sample}

Our population sample is composed of all firms that have introduced at least one product in the US SSI. Product introduction data were taken from Infotrac's General Business File ASAP and PROMT database (former Predicast) that reports several categories of events classified by industrial sectors, obtained from an extensive set of trade journals, magazines and other specialized press. We searched for 
Table 1. Product Niches in the SSI

\begin{tabular}{ll}
\hline Niche & Description \\
\hline Authentication-digital signature & $\begin{array}{l}\text { Products for the authentication of digital documents with a } \\
\text { copyrighted mark } \\
\text { Programs that detect and clean viruses from computers }\end{array}$ \\
Antivirus & $\begin{array}{l}\text { Products aimed to secure the integrity of sensible data } \\
\text { stored in hard drives }\end{array}$ \\
Firewalls & $\begin{array}{c}\text { A sort of checking door between different networks } \\
\text { Utility software } \\
\text { proper execution of the operating system and applications, } \\
\text { giving the possibility to re-create the content of some } \\
\text { data packages lost } \\
\text { Network security management packages that guarantee the } \\
\text { high performing functioning of different networks }\end{array}$ \\
Network security & and management
\end{tabular}

Source: Our elaboration from Infotrac according to a six-digit SIC code classification

all press articles that reported a 'product announcement', a 'new software release' and a 'software evaluation' in the SSI (SIC code 73726) from 1980 to 1998. Then, from each article, we extracted the name of the company, the event date and the six-digit SIC code for the product. We found that the first product was introduced in 1989. From 1989 to 1998 , we registered 270 different entrants that had introduced 1125 different products. All products were classified in six different niches according to their SIC code classification (see Table 1). We also cleaned our data to eliminate eventual product double-counting. Our sample includes both US and non-US firms (24.4\%). Although the announcements were all from the US press, some of these firms may also have competed in the international market that is $40 \%$ smaller than the US market (International Data Corporation 1999).

We triangulated different databases to validate exit from the US market. Specifically, we checked:

1 The US (www.uspto.gov) trademark databases looking for firms' 'live' security software trademarks. Trademarks are withdrawn if the firm is not actually using them in the market. In fact, since the US represents the most important market for software products, firms that want to operate in this market, regardless of their nationality, should own at least one 'live' trademark there.

2 Some financial databases - Hoover's (www.hoovers.com), Mergent on Line (www.mergentonline.com), Bureau Van Djik's Icarus, Jade and Amadeus (www.bvdep.com) — for any firm's balance sheets.

3 The Infotrac Company Resource Data Center and the Infotrac PROMT for any press articles that included news of firms (acquisition, bankruptcy, shutdowns).

4 National yellow pages, software directories and SEC filings (for different years).

Since we have searched for a firm's information until the year 2000, we do not have a right-censoring problem at 1998 . Note that $78 \%$ of the exits represent the complete termination of a firm's activity and the remaining $22 \%$ accounts for an exit from the US SSI. The final sample is composed of 604 company-year observations with 162 exit events. 


\section{Independent Variables}

\section{Versioning}

This time-variant variable (versioning) is equal to the cumulative number of new versions of the entry product, i.e. the product that has spurred a firm's entry into the US SSI. The variable is calculated for each year of a firm's permanence in the market. For example, this means that if CheckPoint entered in 1994 introducing a firewall, we have computed the cumulative number of new versions of this product released by CheckPoint till its exit (or till 1998 if the firm still exists). The entry product niche turns out to be particularly important for young ventures because it usually creates a strong reputation effect and sustains the competitive advantage in the preliminary phases of competition (Kazanjian and Rao 1999). Moreover, any subsequent niche specialization strategy is usually pursued in the same niche that facilitated entry (Debruyne et al. 2002). At the same time, the result of our interviews with some managers of SSI companies confirms the importance of building up a firm's reputation based on the product that has spearheaded its market entry.

\section{Product Portfolio Broadening}

This variable (Berry) is once again time variant and measures the Berry index of dispersion, annually, for the cumulative number of products the firm has released in the US SSI. Specifically, the Berry index is equal to

$$
B_{t}=1 \sum_{t=1}^{\mathrm{n}} X_{t}^{2}
$$

where $X_{t}$ is the share of products in niche $i$ over the total number of products at time $t$. As discussed above, there are six major niches in the SSI. We multiplied this value by 100 so that Berry varies theoretically from 100 (maximum differentiation) to 0 (no differentiation). The Berry index is a quite precise, standard measure of dispersion. Other proxies used in the literature are the following: Carroll et al. (1996) employ a year dummy to capture an overall industry differentiation effect; Dobrev et al. (2002) use the min-max difference in engine power output to measure niche width in the automobile industry; Sorenson (2000) measures differentiation in the computer workstation industry by counting the cumulative number of products a firm offers.

\section{Mixed Strategy}

Our aim is to test whether the versioning and product portfolio broadening strategies reveal any interaction with each other. Empirically we can address this issue simply by constructing a new covariate equal to the product (versioning*Berry) of the versioning and Berry variables.

\section{Controls}

We introduce several time-variant and time-invariant control variables following standard practice in the literature (Sorenson 2000). Time-invariant control variables capture for the effects of pre-entry conditions, and are frequently used proxies in the industrial organization tradition (Audretsch 1991; Klepper 2002). 
First of all, we introduce a firm's age and size at market entry to proxy scale and experience effects. Age at entry (entry age) is calculated as the difference between the year of entry and the year of a firm's foundation. We proxy size at entry by the stock of trademarks that the firm has registered at the US Patent and Trademark Office (entry trademarks). When dealing with small-tomedium sized, non-listed firms that have entered a new industry, time series of the best proxies for size, such as number of employees or total assets, are difficult to obtain. In addition, in software there are no public accounts of produced units. Earlier studies (e.g. Seethamraju 2003) have found a significant correlation between a firm's sales and its portfolio of trademarks. In addition, we took two further steps to validate our measure. First, we interviewed four managers of SSI firms. The clear message they conveyed was that trademarks are a fairly good indicator of a firm's volume of activity, and that they are normally used to protect every single version of software. For example Symantec, an antivirus provider, registered 84 trademarks of which 15 are related to its core product, Norton, until 1998. Second, for 61 firms in our sample we were able to collect information on the number of employees (using different sources: Bureau Van Djik's Orbis, Icarus, Jade and Amadeus). As a robustness check, we have also performed a hazard regression for this sub-set of firms using employees instead of trademarks (employees and entry employees). Both size measures were introduced in the log specification to smooth nonGaussian size distribution effects.

We controlled for a firm's technological capability that is most probably an important determinant of survival in a science-based industry such as the SSI, with the stock of a firm's patents granted at the US Patent Office (www.uspto.gov) at the year of entry (entry patents). Patent stocks have been used extensively in the innovation literature to measure technological capabilities (e.g. Henderson and Cockburn 1994). We included all patents granted in the US class 380 (cryptography) that is the fundamental technological class in the SSI (Giarratana 2004).

To control for different industry conditions at the time of entry we employed the industry density at the time a firm entered the market (density delay). This is a standard control in survival studies (Carroll et al. 1996; Sorenson 2000) that assumes that initial competition conditions influence the future exit hazard of firms.

Moreover, a large body of the literature has analysed and measured the magnitude and sustainability of first-mover and early-mover advantages (Lieberman and Montgomery 1988). In the SSI, where entry and exit barriers are low, and scale economies are less important, the sustainability paradigm of the firstmover advantage is under the most severe test (Gandal 2001). Nonetheless, early movers in the SSI might benefit from the existence of the same users' switching costs that characterize the software industry as a whole (Torrisi 1998). Users who want to move to a different software provider might need to learn how the new supplier's product works; this is an investment that is already sunk within the software product already in use. Early movers might also benefit from a reputation effect. To test for the presence of first-mover advantages we create a dummy (pioneers) that takes the value 1 if a firm has entered in the period 1989-91, the first 3 years, and 0 otherwise. As explained below, we have also experimented with different time spans. 
Finally, we insert a dummy variable that takes the value of 1 if the organization is a US firm, and 0 otherwise (US firm). This is meant to smooth the possible distortion effect for non-US firms in the US patent and trademark database. Moreover, the US SSI market is the largest in the world, which places local firms at a potential advantage.

We now move to time-variant controls derived largely from the organizational ecology literature (Carroll et al. 1996; Sorenson 2000; Dobrev et al. 2002). To capture the effect of the U-shaped relationship between population density and a firm's exit probability, we include the number of firms operating in the US SSI, for each year together with the square term. Following Carroll et al. (1996), we use the one-year lagged value (density and density ${ }^{2}$ ). Experience in the market is captured by the number of years a firm has competed in the US SSI (age in market). This variable is the difference between a firm's entry year and the current year. Size effects are controlled through the stock of trademarks registered at the US Patent and Trademark Office for every year of a firm's market presence in the US SSI (trademarks).

Table 2 displays the basic statistics for the variables used. In particular, it is worth noting that the average firm age at entry is only 2.66 years, confirming that, in this initial phase of the industry, the young venture is the dominant organizational form. Table 3 provides covariates correlations. To give a flavour for the distribution of our population sample across different product strategies, note that 77 firms have released at least one product in a niche different from their entry niche, 113 firms have released at least two products in their entry niche and 29 have released at least one product in a niche different from their entry niche and two products in their entry niche.

\section{Methodology}

To test our hypotheses, we use a hazard model that estimates the hazard rate, namely the probability of exit from the market in year $t$ conditional on being in the market at time $t-1$. Hazard models draw on hazard functions, which are distribution functions of the duration or spell length for a firm $F(t)=\operatorname{Pr}(T<t)$, where $T$ is the duration. Hazard rates are estimated from hazard functions. They are the rates at which spells are completed at duration $t$, given that they have lasted until $t$,

$$
\lambda(t)=f(t) / S(t)
$$

where

$$
f(t)=d F(t) / d t
$$

is the number of firms that exit the market at time $t$ while

$$
S(t)=1-F(t)=\operatorname{Pr}(T \geq t)
$$

the set of firms whose duration is at least $t$, is the number of firms still at risk at time $t$, i.e. the risk set (Blossfeld and Rohwer 2002). 
Table 2. Descriptive Statistics

\begin{tabular}{lcccr}
\hline Variable & Mean & SD & Min & Max \\
\hline Time variant controls & & & & \\
1. Density & 72.478 & 33.992 & 0 & 116 \\
2. Age in market & 1.023 & 1.439 & 0 & 9 \\
3. Trademarks & 1.568 & 1.380 & 0 & 210 \\
Time invariant controls & & & & \\
4. Entry trademarks & 8.673 & 19.253 & 0 & 186 \\
5. Entry patents & 0.251 & 0.678 & 0 & 6 \\
6. Entry age & 2.668 & 2.483 & 0 & 27 \\
7. Density delay & 75.5 & 41.519 & 3 & 152 \\
8. Pioneers & 0.304 & 0.460 & 0 & 1 \\
9. US firms & 0.766 & 0.423 & 0 & 1 \\
Variables of theoretical interest & & & & \\
10. Versioning & 1.799 & 1.934 & 1 & 22 \\
11. Berry & 2.021 & 9.817 & 0 & 64 \\
12. Versioning*Berry & 6.314 & 41.422 & 0 & 500 \\
\hline
\end{tabular}

Table 3. Correlation Matrix

\begin{tabular}{|c|c|c|c|c|c|c|c|c|c|c|c|c|}
\hline & 1 & 2 & 3 & 4 & 5 & 6 & 7 & 8 & 9 & 10 & 11 & 12 \\
\hline 1 & 1.00 & & & & & & & & & & & \\
\hline 2 & 0.11 & 1.00 & & & & & & & & & & \\
\hline 3 & 0.03 & 0.32 & 1.00 & & & & & & & & & \\
\hline 4 & 0.03 & 0.02 & 0.66 & 1.00 & & & & & & & & \\
\hline 5 & 0.19 & 0.06 & 0.21 & 0.12 & 1.00 & & & & & & & \\
\hline 6 & -0.06 & 0.06 & 0.20 & 0.15 & 0.13 & 1.00 & & & & & & \\
\hline 7 & 0.82 & -0.45 & -0.16 & 0.01 & 0.13 & -0.09 & 1.00 & & & & & \\
\hline 8 & -0.68 & 0.37 & 0.12 & -0.02 & -0.08 & 0.07 & -0.79 & 1.00 & & & & \\
\hline 9 & -0.07 & 0.07 & 0.18 & 0.13 & 0.10 & 0.12 & -0.11 & 0.11 & 1.00 & & & \\
\hline 10 & 0.21 & 0.33 & 0.07 & -0.05 & -0.01 & -0.06 & -0.03 & -0.04 & 0.05 & 1.00 & & \\
\hline 11 & 0.01 & 0.55 & 0.30 & 0.07 & 0.10 & 0.14 & -0.26 & 0.29 & 0.05 & 0.14 & 1.00 & \\
\hline 12 & 0.00 & 0.37 & 0.18 & 0.03 & -0.01 & 0.05 & -0.18 & 0.21 & 0.04 & 0.41 & 0.65 & 1.00 \\
\hline
\end{tabular}

Following earlier works (Sorenson 2000; Dobrev et al. 2002) on firm survival in industry population, we opted for the piecewise exponential model specification that does not make any strong assumption on time dependence. Given the time periods, this model could be expressed as:

$$
\Lambda_{j t}=\exp \left(\alpha_{1}+X_{j t} \beta_{j}\right)
$$

where $X$ is the covariate vector, $\beta$ is the vector of coefficients assumed not to vary across time and $\alpha$ is a constant coefficient associated with the $t$ time period (see Blossfeld and Rohwer 2002: 120).

\section{Results and Discussion}

Table 4 provides the estimation results. Model 1 omits the core covariates, showing only the baseline model with the control variables. Models 2, 3, 4 and 
5 progressively add our covariates of interest. Variable addition increases the model's fit, as shown by the chi-square test of significance. Indeed, model 5 appears the best suited $\left(\chi^{2}=66.36\right.$ vs model $1,34.2$ vs model $2,48.96$ vs model 3,20 vs model 4). Finally, model 6 reports the estimation results for the subsample of firms for which information about the number of employees was available. Our first two hypotheses gain support from the data since firms that introduce a larger number of versions of their entry product or have a broader product scope command a higher probability of survival. In unreported regressions, we have experimented with alternative measures of portfolio broadening (e.g. the cumulative number of niches in which a firm operates) and versioning (e.g. the average level of versioning in all the niches a firm has entered) obtaining similar results. The use of cumulative measures for our product strategies can raise concerns because such measures naturally increase with age and thus with survival. We opted for cumulative measures to better capture the learningby-doing effect mentioned in hypothesis 1 . We also partially address this problem by controlling for the years of a firm's experience in the market. As an additional check we have run a regression in which we used the number (noncumulative) of versions and product breath at $t-1$. Results held unchanged. We have also used the average age of a firm's products as a control for Red Queen dynamics in the market. Because of the high correlation with versioning this additional variable did not display a significant coefficient. A square term for versioning and Berry, albeit positive, has turned out insignificant as well. This finding suggests that the benefits of employing both product strategies outweigh their respective costs at all observed values. Finally, we have also controlled for heterogeneity in the survival rates across different niches through a set of dummy variables. Results were still confirmed.

The coefficient of versioning*Berry defines how one product strategy attenuates or strengthens the effects of the other. Our estimation shows that the interaction covariate has a significant negative impact on the survival probability confirming our last hypothesis.

To interpret our findings better, we report in Table 5 the estimates of the multiplier rate of firm exit conditional on different values of versioning and Berry. A multiplier rate of 1 means that a variable has no effect on the exit rate. A multiplier rate smaller than 1 implies that a particular level of a variable increases the chances of survival. Table 5 explores the change in exit rate due to a more aggressive portfolio broadening strategy for given levels of a versioning strategy, and vice versa. Multiplier rates are computed with a baseline model of a one-product firm: $\mathrm{M}=\exp \left(-.389^{*}\right.$ versioning $-0.097 *$ Berry $+.016^{*}$ versioning*Berry)/exp(- .389). First, note that for low levels of versioning, increasing the degree of portfolio broadening decreases the exit rate. This finding supports our second hypothesis. However, for a sufficiently high level of versioning, an effort to broaden the product offering might have a negative effect on the survival rate according to the third hypothesis. A firm would be better off by being as focused as possible. Specifically, the advantage shifts from being multi-niche to being single-niche when versioning is above 7 . We now turn to the second part of Table 5 where we analyse the change in exit rate due to a more aggressive versioning strategy for given levels of a portfolio broadening strategy. 
Table 4. Hazard Rates for Piecewise Exponential Model for SSI Market Exit, 1989-98

\begin{tabular}{|c|c|c|c|c|c|c|}
\hline $\begin{array}{l}\text { Independent } \\
\text { variables }\end{array}$ & Model 1 & Model 2 & Model 3 & Model 4 & Model 5 & Model 6 \\
\hline \multicolumn{7}{|l|}{ Time-variant controls } \\
\hline Density & $\begin{array}{c}-4.423 * * \\
(0.001)\end{array}$ & $\begin{array}{c}-4.510 * * \\
(0.001)\end{array}$ & $\begin{array}{c}-4.605^{* *} * \\
(0.002)\end{array}$ & $\begin{array}{c}-4.343 * * \\
(0.001)\end{array}$ & $\begin{array}{l}-4.711 * * \\
(0.002)\end{array}$ & $\begin{array}{c}-3.772 * * \\
(0.012)\end{array}$ \\
\hline Density2 & $\begin{array}{l}0.019 * * \\
(0.000)\end{array}$ & $\begin{array}{l}0.019 * * \\
(0.001)\end{array}$ & $\begin{array}{l}0.019 * * \\
(0.001)\end{array}$ & $\begin{array}{l}0.018^{* *} * \\
(0.000)\end{array}$ & $\begin{array}{l}0.020 * * \\
(0.002)\end{array}$ & $\begin{array}{l}0.045^{* * *} \\
(0.001)\end{array}$ \\
\hline Age in market & $\begin{array}{l}-0.646 * * \\
(0.100)\end{array}$ & $\begin{array}{c}-0.726 * * \\
(0.107)\end{array}$ & $\begin{array}{c}-0.416^{* *} \\
(0.132)\end{array}$ & $\begin{array}{c}-0.462^{* *} \\
(0.129)\end{array}$ & $\begin{array}{c}-0.454^{* *} \\
(0.131)\end{array}$ & $\begin{array}{c}-0.733^{* *} \\
(0.251)\end{array}$ \\
\hline Trademarks & $\begin{array}{c}-0.142 * \\
(0.065)\end{array}$ & $\begin{array}{c}-0.127^{*} \\
(0.065)\end{array}$ & $\begin{array}{c}-0.103 \\
(0.070)\end{array}$ & $\begin{array}{c}-0.088 \\
(0.076)\end{array}$ & $\begin{array}{c}-0.087 \\
(0.076)\end{array}$ & - \\
\hline Employees & - & - & - & - & - & $\begin{array}{c}1.568 \\
(1.623)\end{array}$ \\
\hline \multicolumn{7}{|l|}{ Time-invariant controls } \\
\hline Entry trademarks & $\begin{array}{c}0.004 \\
(0.003)\end{array}$ & $\begin{array}{c}0.003 \\
(0.004)\end{array}$ & $\begin{array}{c}0.002 \\
(0.004)\end{array}$ & $\begin{array}{c}0.000 \\
(0.005)\end{array}$ & $\begin{array}{c}0.000 \\
(0.005)\end{array}$ & - \\
\hline Entry employees & & & & & & $\begin{array}{c}1.332 \\
(1.153)\end{array}$ \\
\hline Entry patents & $\begin{array}{c}-0.506 * * \\
(0.122)\end{array}$ & $\begin{array}{c}-0.528 * * \\
(0.120)\end{array}$ & $\begin{array}{c}-0.449 * * \\
(0.132)\end{array}$ & $\begin{array}{c}-0.443 * * \\
(0.131)\end{array}$ & $\begin{array}{c}-0.439 * * \\
(0.131)\end{array}$ & $\begin{array}{c}-0.395^{* *} \\
(0.184)\end{array}$ \\
\hline Entry age & $\begin{array}{c}0.010 \\
(0.020)\end{array}$ & $\begin{array}{c}-0.003 \\
(0.024)\end{array}$ & $\begin{array}{c}0.020 \\
(0.015)\end{array}$ & $\begin{array}{c}0.013 \\
(0.016)\end{array}$ & $\begin{array}{c}0.013 \\
(0.016)\end{array}$ & $\begin{array}{c}0.009 \\
(0.018)\end{array}$ \\
\hline Density delay & $\begin{array}{l}-0.051 * * \\
(0.009)\end{array}$ & $\begin{array}{c}-0.064 * * \\
(0.011)\end{array}$ & $\begin{array}{c}-0.046^{* *} \\
(0.009)\end{array}$ & $\begin{array}{c}-0.056^{* *} \\
(0.010)\end{array}$ & $\begin{array}{c}-0.056^{* * *} \\
(0.010)\end{array}$ & $\begin{array}{c}-0.067 * * \\
(0.013)\end{array}$ \\
\hline Pioneers & $\begin{array}{c}-0.054 \\
(0.342)\end{array}$ & $\begin{array}{c}-0.360 \\
(0.307)\end{array}$ & $\begin{array}{c}-0.236 \\
(0.310)\end{array}$ & $\begin{array}{c}-0.491 \\
(0.285)\end{array}$ & $\begin{array}{c}-0.501 \\
(0.283)\end{array}$ & $\begin{array}{c}-0.405^{* *} \\
(0.124)\end{array}$ \\
\hline US firms & $\begin{array}{c}-0.045 \\
(0.143)\end{array}$ & $\begin{array}{c}0.029 \\
(0.144)\end{array}$ & $\begin{array}{c}-0.140 \\
(0.125)\end{array}$ & $\begin{array}{c}-0.024 \\
(0.135)\end{array}$ & $\begin{array}{c}-0.022 \\
(0.135)\end{array}$ & $\begin{array}{c}-0.045 \\
(0.199)\end{array}$ \\
\hline \multicolumn{7}{|l|}{ Core variables } \\
\hline Versioning & - & $\begin{array}{c}-0.377 * * \\
(0.060)\end{array}$ & - & $\begin{array}{c}-0.370^{* * *} \\
(0.064)\end{array}$ & $\begin{array}{c}-0.389 * * \\
(0.062)\end{array}$ & $\begin{array}{c}-0.401^{* *} * \\
(0.065)\end{array}$ \\
\hline Berry & - & - & $\begin{array}{c}-0.051^{* *} * \\
(0.026)\end{array}$ & $\begin{array}{c}-0.051^{* * *} \\
(0.024)\end{array}$ & $\begin{array}{c}-0.097 * * \\
(0.023)\end{array}$ & $\begin{array}{c}-0.089 * * \\
(0.021)\end{array}$ \\
\hline Versioning*Berry & - & - & - & - & $\begin{array}{l}0.016^{* * *} \\
(0.003)\end{array}$ & $\begin{array}{l}0.021^{* * *} \\
(0.002)\end{array}$ \\
\hline $\log L$ & 913.33 & 903.33 & 888.85 & 896.23 & 880.15 & 915.86 \\
\hline
\end{tabular}

162 exits, 604 organization-years. $* p<0.10, * * p<0.05$. Heteroskedastic consistent standard errors in parentheses. Model 6 accounts for 168 organization-years.

Again, we observe that versioning produces an advantage when the firm has a narrow product scope (according to hypothesis 1); however, when a firm that has a broad product scope pursues an aggressive versioning strategy, this has a negative effect on the survival rate. The switch occurs when Berry takes the value of 25 .

Model 6 shows that the results are confirmed for the sub-sample of firms for which we could count on employee data; interestingly enough, even in this case, firm size does not show a significant coefficient. This is not that surprising: three of the most successful firms in the SSI - CheckPoint, Verisign and RSA Data Security — accounted for fewer than 800 employees in 1998; while in the hardware sector a successful company such as Sun Microsystems, founded in 1982 with 4 employees, already accounted for more than 4,000 in 1987. This finding also confirms the greater scalability of software firms compared to hardware 
Table 5. Multiplier Rates of Exit

\begin{tabular}{|c|c|c|c|c|c|c|}
\hline \multirow[b]{2}{*}{ Berry } & \multicolumn{6}{|c|}{ Versioning } \\
\hline & 1 & 2 & \multicolumn{2}{|c|}{5} & 10 & 20 \\
\hline 1 & 0.923 & 0.635 & \multicolumn{2}{|c|}{0.208} & 0.032 & 0.001 \\
\hline 5 & 0.668 & 0.490 & \multicolumn{2}{|c|}{0.194} & 0.041 & 0.002 \\
\hline 10 & 0.446 & 0.355 & \multicolumn{2}{|c|}{0.178} & 0.056 & 0.006 \\
\hline 20 & 0.199 & 0.186 & \multicolumn{2}{|c|}{0.150} & 0.105 & 0.052 \\
\hline 30 & 0.089 & 0.097 & \multicolumn{2}{|c|}{0.126} & 0.196 & 0.470 \\
\hline \multirow[t]{2}{*}{44} & 0.040 & 0.051 & & & 0.365 & 4.283 \\
\hline & \multicolumn{6}{|c|}{ Berry } \\
\hline Versioning & 0 & 5 & 10 & 20 & 30 & 40 \\
\hline 1 & 1.000 & 0.668 & 0.446 & 0.199 & 0.089 & 0.040 \\
\hline 3 & 0.678 & 0.490 & 0.355 & 0.186 & 0.097 & 0.051 \\
\hline 6 & 0.211 & 0.194 & 0.178 & 0.150 & 0.126 & 0.106 \\
\hline 11 & 0.030 & 0.041 & 0.056 & 0.105 & 0.196 & 0.365 \\
\hline 21 & 0.001 & 0.002 & 0.006 & 0.052 & 0.470 & 4.283 \\
\hline
\end{tabular}

Note: Changes in the variable in rows for a given level of the variable in columns.

companies. However, it does not exclude the fact that firm size could acquire importance in a more mature phase of the industry.

In sum, the results suggest two possible routes to success in the SSI: (1) a niche product leadership, i.e. specializing with aggressive versioning in a particular niche and keeping the product at the technological frontier; (2) a onestop-shop strategy, i.e. offering a complete security package to customers, which may also include consultancy services. The most famous firms pursuing niche product leadership are CheckPoint (firewall), Aladdin (data protection) and Symantec (antivirus). Firms that have championed the second strategy are Verisign, Security Dynamics and Network Associates, supplying a large set of products from consultancy to the integration of applications. This vision is clearly expressed in the words of Zach Nelson, chief strategy officer at Network Associates: 'We went aggressively after the one-stop-shop strategy five years ago, and we were way ahead of the market in terms of the customers' willingness to accept all of those products from one vendor' (eWeek 2000).

Our results also provide evidence of the trade-off between strategies that naturally lead to an evolution of a population into two (or more) strategic groups (Carroll 1985; Dobrev et al. 2001). It is interesting to note that until 1998 the demand structure in the SSI reflected two distinct resource spaces. On one side were large ICT firms representing technology-skilled, highly selective customers who tend to choose the best products on the market (hardware, telecommunication and semiconductor producers); on the other side, we have less 'techy' consumers such as banks, financial institutions and credit card companies (Giarratana 2004) that demand global security packages.

As far as it concerns our control variables, the dummy for early industry entrants (pioneers) is not significant at all, suggesting that firms that have 
entered the US SSI in its early days do not show a higher probability of survival. This result seems quite robust. Indeed, we have experimented with different time windows for early entrants, as well as with a time trend (= year of firm entry - 1989), and always obtained insignificant coefficients. A plausible explanation relies on the high degree of uncertainty at the nascent stages of a new industry that moderates the benefits of first-mover advantages. In addition, the evidence concerning first-mover advantages comes typically from more stable and concentrated industries where pioneers end up enjoying larger scale economies, lead time and network effects. Indeed, only weak evidence of firstmover advantages has shown up in the very few studies focusing on Schumpeterian environments (Makadok 1998; Gandal 2001).

As expected, pre-entry technological capabilities play an important role in influencing the survival rate. If all other variables are held at their mean values, entrants endowed with, for example, six patents are $88.8 \%$ more likely to survive than entrants with only one patent $(\exp [-0.439 *(6-1)]$, using estimates from model 5). Industry density shows an effect in line with the population ecology tradition (Carroll et al. 1996; Dobrev et al. 2002): positive for the density term, negative for the square, suggesting that both legitimization and competition play a role in the US SSI. The negative sign of density delay, which suggests a lack of crowding out at entry, could be explained by the high growth rates of SSI during its early stages of development. Some authors have found that the effect of density depends on the level of analysis (i.e. see Lomi 2000). Unreported regressions using niche-level density confirms the above finding. Finally, by comparing firm experience on the market with firm size, one reaches the conclusion that, in the US SSI, experience has a more robust effect than size. Indeed, the trademarks variable loses significance when we account for a firm's product strategies, while age in market always remains significant (note that the same results hold when we use the number of employees as a measure of size). This effect could be due to some idiosyncratic features specific to the software industry: scarce scale economies, crucial role of learning from users, and importance of product reputation (Torrisi 1998; Von Hippel 1986).

\section{Conclusion}

In this paper we have investigated empirically the determinants of firm survival in the US security software industry, a prototypical example of a Schumpeterian environment, where the young venture is the dominant organizational form.

Our findings suggest that post-entry product strategies of versioning and portfolio broadening are important in explaining survival rates even after controlling for the standard drivers of viability highlighted by the industrial organization (Audretsch 1991; Gerosky 1995; Klepper 2002) and population ecology traditions (Hannan and Freeman 1989; Carroll et al. 1996; Sorenson 2000; Dobrev et al. 2002). This significant effect of post-entry product strategies fits perfectly within a framework where learning (Garud and Kumaraswamy 1993) and Red Queen competition (Barnett and Sorenson 2002) play a major role. 
Moreover, we show that focus on post-entry product strategies improves firm viability. Therefore, a coherent strategic positioning in the SSI implies either the exploitation of a versioning strategy for achieving single-niche leadership, or the broadening of the product scope in order to serve the market as a one-stop-shop provider. These findings are consistent with the common wisdom in the organizational learning literature that advocates a trade-off between strategies that require different learning processes - for example, exploration vs exploitation (March 1991). In addition, such a trade-off provides the microdynamics for the partition of the population of SSI firms into two different groups (Dobrev et al. 2001; Kim et al. 2003). In fact, resource partitioning theory postulates that mixed strategies reduce viability (Carroll 1986). As a matter of fact, the demand for security software products is segmented into high-tech customers (who demand the best product in the market) and low-tech customers (who need a comprehensive security package), so that the negative effect of the interaction of our two product strategies could be explained as the result of this bimodal resource distribution. We think that these findings are not just specific to the US SSI, but can also be applied to other high-tech industries such as computer hardware and semiconductors, where the distribution of customers' preferences is similar, while product innovation and versioning are major drivers of viability. Only future research can, however, provide support to this conjecture.

As secondary findings, we show that firm age and size at entry play a marginal role, whereas we confirm the importance of pre-entry technological capabilities and post-entry market experience. We relate these stylized facts to the particular features of the SSI, where entry and exit barriers are low, scale economies are limited, and the route to success is through market experience, learning from users, technological competencies and reputation (Torrisi 1998; Von Hippel and Kats 2002). Moreover, in line with previous empirical studies of Schumpeterian environments (Gandal 2001), pioneer firms do not command higher survival rates than later entrants. However, given the relatively short time window of our study, one has to interpret these findings with caution. In fact, we cannot exclude that entry time and size could be pivotal at some later stages of industry evolution.

Finally, compared with classical survival studies in large sunk cost industries (Sorenson 2000, Carroll et al. 1996; Dobrev et al. 2002; Klepper 2002), the US SSI elevates to the central stage the crucial role of product strategies, market orientation, technological competences and learning. However, needless to say, further research into other Schumpeterian environments is needed to assess whether our findings can be generalized.

\section{Notes}

We thank Elisabeth Cabrera, Julio de Castro, Luis Gómez Mejía, Isabel Gutierrez, Giacomo Negro, Olav Sorenson, the editor (Raghu Garud), four anonymous reviewers and seminar participants at the Instituto de Empresa (Madrid), at the 2nd Econ-Change workshop (London), at the 10th ISS Conference (Milan) and at the ZEW workshop on Firm Entry and Exit (Jena) for helpful comments and suggestions on an earlier draft. We gratefully acknowledge financial support from the European Commission (HPSE-CT-2002-00146), and the Spanish Ministry of Science and Technology (SEC2003-03797). 


\section{References}

Abernathy, W. J., and J. Utterback

1978 'Patterns of industrial innovation'. Technology Review 80/2: 41-47.

Audretsch, D.

1991 'New-firm survival and the technological regime'. Review of Economics and Statistics 73/3: 441-450.

Barnett, W. P., and J. H. Freeman

2001 'Too much of a good thing? Product proliferation and organization failure'. Organization Science 12/3: 539-558.

Barnett, W. P., and O. Sorenson

2002 'The red queen in organizational creation and development'. Industrial and Corporate Change 11/2: 289-325.

Bayus, B. L., and R. Agarwal

2006 'Product Strategies and Firms Survival in Technologically Dynamic Industries'. Unpublished manuscript.

Blossfeld, H. P., and G. Rohwer

2002 Techniques in event history modeling: New approaches to casual analysis. Mahwah, NJ: Lawrence Erlbaum Associates.

Carroll, G. R.

1985 'Concentration and specialization: Dynamics of niche width in population of organizations'. American Journal of Sociology 90/6: 1262-1283.

Carroll, G. R., and M. T. Hannan

1989 'Density delay in the evolution of organizational populations: A model and 5 empirical tests'. Administrative Science Quarterly 34/3: 411-430.

Carroll, G. R., L. S. Bigelow, M. D. L.

Seidel, and L. B. Tsai

1996 'Fates of de-novo and de-alio producers in the American automobile industry 1885-1981', Strategic Management Journal 17: 117-137.

Covin, J. G., and D. P. Slevin

1989 'Strategic management of small firms in hostile and benign environments'. Strategic Management Journal 10/1: 75-87.

Cyert, R. M., and J. G. March

1963 A behavioral theory of the firm. Englewood Cliffs, NJ: Prentice Hall.

Debruyne, M., R. Moenaert, A. Griffin, S. Hart, E. Hultink, and H. Robben
2002 'The impact of new product launch strategies on competitive reaction in industrial markets'. Journal of Product Innovation Management 19/2: 159-170.

Dobrev, S. D., T. Y. Kim, and M. T. Hannan

2001 'Dynamics of niche width and resource partitioning'. American Journal of Sociology 106/5: 1299-1337.

Dobrev, S. D., T. Y. Kim, and G. R. Carroll

2002 'The evolution of organizational niches: US automobile manufacturers, 1885-1998'. Administrative Science Quarterly 47/2: 233-264.

Dowell, G., and A. Swaminathan

2000 'Racing and back-pedalling into the future: New product introduction and organizational mortality in the US bicycle industry, 1880-1918'. Organization Studies 21/2: 405-431.

Electronic Business

1999 'Israel's Safety Net'. Electronic Business 25/5: 72.

Ernst \& Young

2004 Global Biotech Report. Available at www.ey.com.

eWeek

2000 'One-stop security? Vigilinx, Network Associates retry superstore approach'. eWeek 26/2/2000: 11.

Freeman, J., and M. T. Hannan

1989 'Setting the record straight on organizational ecology: Rebuttal to Young'. American Journal of Sociology 95/2: 425-439.

Gandal, N.

2001 'The dynamics of competition in the internet search engine market'. International Journal of Industrial Organization 19/7: 1103-1117.

Gandal, N., S. Markovich, and M. Riordan 2002 'Ain't it "suite"? Strategic bundling in the PC office software market'. Unpublished manuscript.

Gans, J. S., and S. Stern

2003 'The product market and the market for "Ideas": Commercialization strategies for technology entrepreneurs'. Research Policy 32/2: 333-350.

Garud, R., and A. Kumaraswamy

1993 'Changing competitive dynamics in network industries: An exploration of 
Sun Microsystems open systems strategy'. Strategic Management Journal 14/5: 351-369.

Geroski, P.

1995 'What do we know about entry?' International Journal of Industrial Organization 13/4: 421-440.

Giarratana, M. S.

2004 'The birth of a new industry: Entry by startups and the drivers of firm growth. The case of encryption software'. Research Policy 33/5: 787-806.

Hannan, M. T.

1997 'Inertia, density and the structure of organizational populations: Entries in European automobile industries, 1886-1981'. Organization Studies 18/2: 193-228.

Hannan, M. T., G. R. Carroll, S. D. Dobrev, and J. Han

1998a 'Organizational mortality in European and American automobile industries Part I: Revisiting the effects of age and size'. European Sociological Review 14/3: 279-302.

Hannan, M. T., G. R. Carroll, S. D. Dobrev, and $\mathbf{J}$. Han

1998b 'Organizational mortality in European and American automobile industries Part II: Coupled clocks'. European Sociological Review 14/3: 303-313.

Henderson, R., and I. Cockburn

1994 'Measuring competence? Exploring firm effects in pharmaceutical research'. Strategic Management Journal 15: 63-84.

Ilinitch, A., R. D'Aveni, and A. Lewin 1996 'New organizational forms and strategies for managing in hypercompetitive environments'. Organization Science 7/3: 211-220.

International Data Corporation (IDC)

1999 Software Security Market Research. Annual Report.

Kazanjian, R., and H. Rao

1999 'The creation of capabilities in new ventures: A longitudinal study'. Organization Studies 20/1: 125-137.

Kekre, S., and K. Srinivasan

1990 'Broader product line: A necessity to achieve success'. Management Science 36/10: 1216-1231.

Kim, T. Y., S. D. Dobrev, and L. Solari

2003 'Festina lente: Learning and inertia among Italian automobile producers,
1896-1981'. Industrial and

Corporate Change 12/6: 1279-1301.

Klepper, S.

2002 'Firm survival and the evolution of oligopoly'. Rand Journal of Economics 33/1: 37-61.

Lancaster, $\mathrm{K}$

1990 'The economics of product variety'. Marketing Science 9/3: 189-211.

Lieberman, M., and D. Montgomery

1988 'First-mover advantages'. Strategic Management Journal 9: 41-58.

Lomi, A.

2000 'Density dependence and spatial duality in organizational founding rates: Danish commercial banks, 1846-1989'. Organization Studies 21/2: 433-461.

McKendrick, D. G., J. Jaffee, G. R. Carroll, and O. M. Khessina

2003 'In the bud? Analysis of disk array producers as a (possibly) emergent organizational form'. Administrative Science Quarterly 48/1: 348-381.

Makadok, R.

1998 'Can first-mover and early-mover advantages be sustained in an industry with low barriers to entry/imitation?' Strategic Management Journal 19/7: 683-696.

March, J. G.

1991 'Exploration and exploitation in organization learning'. Organization Science 2/1: 71-87.

Miller, D., and P. H. Friesen

1984 'A longitudinal study of the corporate life cycle'. Management Science 30/10: 1161-1183.

Schmalensee, R.

2000 'Antitrust issues in Schumpeterian industries'. American Economic Review 90/2: 192-197.

Seethamraju, C.

2003 'The value relevance of trademarks' in Intangible assets: Values, measures and risks. J. Hand and L. Baruch (eds). New York: Oxford University Press.

Shapiro, C., and H. R. Varian

1998 'Versioning: The smart way to sell information'. Harvard Business Review 76/6: 106-107.

Siggelkow, N.

2003 'Why focus? A study of intraindustry effects'. Journal of Industrial Economics 51/2: 121-148. 
Sorenson, O.

2000 'Letting the market work for you: An evolutionary perspective on product strategy'. Strategic Management Journal 21/2: 277-292.

Torrisi, S.

1998 Industrial organisation and innovation: An international study of the software industry. Cheltenham, UK:

Edward Elgar.

Tushman, M. L., and P. Anderson

1986 'Technological discontinuities and organizational environments'. Administrative Science Quarterly 31/3: 439-465.

Von Hippel, E.

1986 'Lead users: A source of novel product concepts'. Management Science 32/7: 791-805.

Von Hippel, E. and R. Katz

2002 'Shifting innovation to users via toolkit'. Management Science 48/07: 821-833.
Marco

S. Giarratana

Andrea Fosfuri
Marco S. Giarratana (PhD, Sant'Anna School of Advanced Studies, 2003) is Assistant Professor of Management in the Department of Business Administration at Carlos III University, Madrid. His research interests range from industrial dynamics to firm strategy and innovation. His work has been recently published in Research Policy.

Address: Universidad Carlos III de Madrid, Department of Business Administration, Calle Madrid 126, 28903 Getafe Madrid, Spain.

Email: marco.giarratana@uc3m.es

Andrea Fosfuri (PhD, Universitat Pompeu Fabra, 1998) is associate professor of management in the Department of Business Administration at Carlos III University, Madrid. His research is at the interface between economics and strategic management, and focuses on licensing, knowledge spillovers and industry evolution. Recent work has been published in Management Science, Strategic Management Journal and Research Policy. Address: Universidad Carlos III de Madrid, Department of Business Administration, Calle Madrid 126, 28903 Getafe Madrid, Spain.

Email: andrea.fosfuri@uc3m.es 